\title{
Postembryonic Alteration of Transmitter Phenotype in Individually Identified Peptidergic Neurons
}

\author{
N. J. Tublitz and A. W. Sylwester \\ Institute of Neuroscience, University of Oregon, Eugene, Oregon 97403
}

\begin{abstract}
Many neurons are now known to undergo dramatic morphological or biochemical changes long after they have completed differentiation and maturation. The ability of fully mature neurons to alter their transmitter phenotype has been amply demonstrated in culture, but direct in vivo data on single neurons have been difficult to obtain. Here we show that a set of $\mathbf{4}$ individually identified neurosecretory neurons in the moth Manduca sexta, previously demonstrated to contain the peptide hormone bursicon, also stain with a monoclonal antibody directed against 2 insect cardioacceleratory peptides (CAPs). These lateral cells exhibit CAP-like immunoreactivity in larvae but not in pupae or adults, in contrast to other CAP-containing neurons which are strongly immunoreactive in all postembryonic stages. Biochemical analyses using high-pressure liquid chromatography confirm that the lateral neurons in larvae contain $\mathrm{CAP}_{2}$, one of the CAPs. CAP measurements of cell clusters containing these cells indicate high levels only in caterpillars. When the same neurosecretory cells are individually dissected and assayed for CAP bioactivity, high CAP levels are again found in larvae, whereas the same neurons in pupae show no such CAP bioactivity. Simultaneous determinations of both bursicon and CAP levels in single lateral cells indicate that these cells express high levels of CAP activity and low amounts of bursicon in larvae yet are solely bursicon-containing in pupae and adults. Thus, by demonstrating that these cells alter their secretory profile in vivo during metamorphosis, our results confirm the notion that functionally mature neurons are capable of altering their transmitter expression after the completion of embryonic development.
\end{abstract}

During development cells reach their terminal phenotype through a series of progressive specializations by a process known as differentiation. It was for many years generally assumed that the cell did not undergo any further major developmental changes once differentiation was completed and the mature phenotype expressed. During the past 15 years, however, the irreversible nature of neuronal differentiation has come under scrutiny because several different neuronal cell types in invertebrates and vertebrates have been shown to exhibit striking alterations in

\footnotetext{
Received May 1, 1989; revised June 8, 1989; accepted June 27, 1989.

We thank Dr. P. H. Taghert for his generous gift of the anti-CAP antibody. We are also grateful to Mr. Kendal Broadie, and Drs. Mandu Kerr, Judith Eisen, Barry Trimmer, and Janis Weeks for their helpful comments on this manuscript. This work is supported by USPHS grants NS-24613 and RCDA NSO1258 and a Sloan Fellowship to N.J.T.

Correspondence should be addressed to Dr. N. J. Tublitz at the above address. Copyright (C) 1990 Society for Neuroscience $0270-6474 / 90 / 010161-08 \$ 02.00 / 0$
}

their biochemical and morphological properties both in vitro and in vivo (Patterson and Chun, 1977; Gesser and Larsson, 1985; Coulombe and Bronner-Fraser, 1986; Koizumi and Bode, 1986; Lichtman et al., 1987; Schotzinger and Landis, 1988).

The ability of neurons to change their properties after the completion of embryogenesis is perhaps best documented for cells from the autonomic nervous system. Many studies have shown that sympathetic neurons, which originally express a noradrenergic phenotype, become cholinergic in certain situations (Patterson and Chun, 1977; Patterson, 1978). This has been repeatedly demonstrated in cell culture, where noradrenergic cells isolated from neonatal sympathetic ganglia can acquire cholinergic function by appropriate manipulation of the cell culture medium (Johnson et al., 1976; Patterson and Chun, 1977; Potter et al., 1980). Even single cultured neurons, dissociated from rat superior cervical ganglia, can be induced to display a variety of cholinergic properties (Potter et al., 1986). Additional experiments in vivo on the development of a cholinergic phenotype by sympathetic neurons innervating rat sweat gland have corroborated the culture studies and have shown that these neurons are characterized in vivo by high levels of choline acetyltransferase and acetylcholinesterase and by cholinergic transmission (Landis and Keefe, 1983; Leblanc and Landis, 1986; Stevens and Landis, 1987). Noradrenergic sympathetic neurons can even express cholinergic function in vivo if allowed to innervate a cholinergic target (Schotzinger and Landis, 1988).

Although the elegant in vitro and in vivo work on sympathetic cells has illustrated the ability of those neurons to switch their secretory profile, it has proved difficult to unequivocally demonstrate that such a change in transmitter expression occurs in vivo at the level of a single, identified cell. Variations in transmitter phenotype in specific peptidergic neurons using immunocytochemical techniques have been reported in the pond snail, Lymnaea stagnalis (Gesser and Larsson, 1985), and in Hydra (Koizumi and Bode, 1986), yet the significance of these changes is unclear. Here we report on a set of individually identifiable, peptide-containing neurons in the ventral nerve cord (VNC) of the tobacco hawkmoth, Manduca sexta, that alter their transmitter profile in vivo after the completion of embryogenesis.

Using physiological, endocrinological, and ultrastructural criteria, Taghert and Truman $(1982 \mathrm{a}, \mathrm{b})$ demonstrated that each abdominal ganglion in all postembryonic stages in Manduca contains a small number of individually identifiable neurosecretory cells. In each larval ganglion (Fig. 1A), there are 6 pairs of neurosecretory somata, of which 4 pairs are positioned laterally and the remaining 2 pairs are located medially. The axons of these neurons project to the transverse nerve (TN), a seg- 
A

LARVA

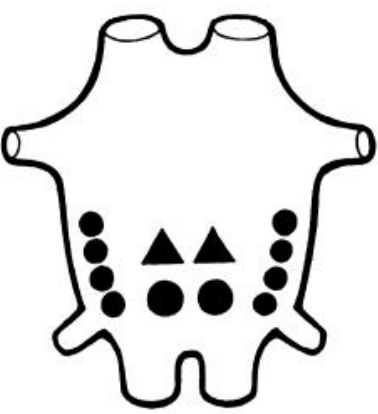

B

ADULT

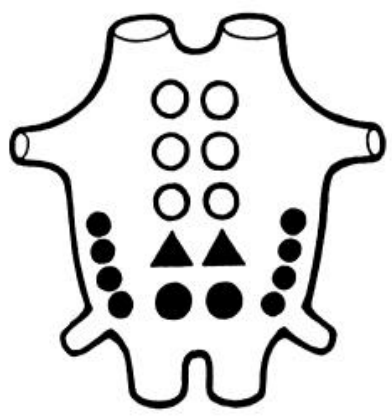

Figure 1. Immunocytochemical labeling of neurons in larval and pupal abdominal ganglion of the tobacco hornworm, Manduca sexta. A, B, Cell body location of all central neurosecretory cells that project to the transverse nerve (TN) in an unfused abdominal ganglion in $(A)$ a 5th-instar larva and $(B)$ pharate adult (modified from Taghert and Truman, 1982a, b). Open and filled circles, cells that project to posterior TN; filled triangles, cells that terminate in the anterior TN. Note that the pharate adult contains, in addition to the larval complement of cells, 3 pairs of midline, CAP-containing neurons that first appear during metamorphosis (Taylor and Truman, 1974; Taghert and Truman, 1982a, b; Tublitz and Truman, 1985b-d). $C$, Immunocytochemical whole-mount staining using the $6 \mathrm{C} 5$ antibody of the fifth abdominal ganglion taken from day 1 fifth instar. $D$. Camera lucida drawing of the preparation in $C$, illustrating that the antibody stains 4 lateral pairs and 2 midline cells in larvae. $E$, Camera lucida drawing of $6 \mathrm{C} 5$ immunostaining of the fifth abdominal ganglion in a day 8 pupa.
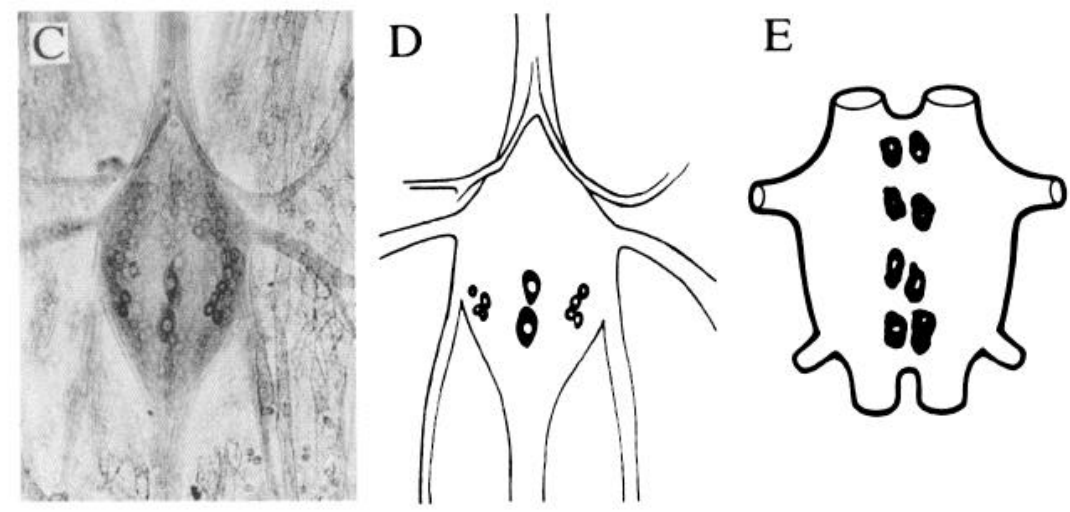

mentally reiterated peripheral nerve that is the major neurohemal release site for the insect VNC (Raabe et al., 1966; Raabe, 1982). The pattern is similar in pupae, except that in addition to the full complement of cells found in larvae, there are 3 newly developing pairs of midline cells that differentiate during metamorphosis (Fig. 1B; Taylor and Truman, 1974; Taghert and Truman, 1982a, b).

The physiology of both groups of cells is similarly well described. Using single-cell bioassay techniques, previous studies (Taghert and Truman, 1982b) showed that each lateral cell contains bursicon, an insect peptide hormone that is released after each molt to initiate cuticular tanning (Truman, 1973; Reynolds, $1977,1983)$. In contrast, 4 of the 5 pairs of midline neurons (Fig. $1 B$ ), including the 6 that differentiate during adult development, have been demonstrated to synthesize and release 2 cardioregulatory peptides, the cardioacceleratory peptides (CAPs; Tublitz and Truman, 1985c, d). The function of the CAPs varies depending on the stage of development: in adults the CAPs act as neurohormones modulating the endogenous myogenic rhythm of the Manduca heart during adult emergence (Tublitz and Truman, 1985a, b; Tublitz and Evans, 1986) and flight (Tublitz, 1989) whereas in the embryo and in 5th-instar larvae, they regulate the spontaneous contractions of the hindgut (Broadie et al., 1989; K. K. Edwards, R. Taylor, D. P. Kimble, and N. J. Tublitz, unpublished observations).

Recent immunocytochemical studies, using a monoclonal antibody that recognizes an epitope common to both CAPs (Taghert et al., 1983, 1984), indicate that the lateral neurosecretory cells express, in addition to bursicon, a CAP-like antigen in embryos and throughout all larval instars, but not in adults (Tublitz and Sylwester, 1988; Broadie et al., 1989). From these results we proposed the hypothesis that the lateral cells undergo a change in their transmitter profile during adult development, expressing both bursicon and CAP bioactivity in larvae and only bursicon in pupae and adults. The experiments described in this paper were designed to test this hypothesis.

\section{Materials and Methods}

Animals. Tobacco hornworms, $M$. sexta, were individually reared on an artificial diet (Bell and Joachim, 1976) in a controlled environmental chamber using a 17:7 LD regime with a superimposed thermal period $\left(27^{\circ} \mathrm{C} / \mathrm{L}, 25^{\circ} \mathrm{C} / \mathrm{D}\right)$. Prior to adult emergence, pharate adults were placed in a large breeding chamber and allowed to emerge and mate. The photoperiod and thermal period of this chamber were identical to those of the rearing conditions for larvae except that relative humidity was maintained at a level exceeding $50 \%$ using commercially obtained humidifiers.

$C A P$, bioassay. CAP, levels were quantitatively measured using an isolated pharate adult Manduca heart bioassay as previously described (Tublitz and Truman, 1985a-c; Tublitz, 1989). In short, a portion of the abdominal heart was removed from a pharate adult male, pinned into a small superfusion chamber, and attached to a force transducer (Bionix F-200 Isotonic Displacement Transducer powered by a Bionix Powerpack Ed-1A). The signal from the transducer was amplified and monitored by a window discriminator and digital-to-analog circuits to measure the instantaneous heartbeat frequency. Amplitude and frequency of contraction were recorded continuously on a Gould 2200 chart recorder for later analysis.

Manduca saline of the following composition was used in all experiments (in mM): $6.5 \mathrm{NaCl}, 28.5 \mathrm{KCl}, 5.6 \mathrm{CaCl}_{2}, 16 \mathrm{MgCl}_{2}, 5$ Pipes (dipotassium salt, Sigma), and 173 dextrose. The final $\mathrm{pH}$ was adjusted to $6.7 \pm 0.1$ using a concentrated solution of $\mathrm{HCl}$. During each bioassay, 
the flow rate of saline was maintained at about $80 \mathrm{ml} \mathrm{hr}^{-1}$ through the open perfusion system. All test samples were injected directly into the perfusion system with a $100-\mu \mathrm{l}$ gas-tight Hamilton glass syringe.

Immunocytochemistry. Individual ganglia were dissected away from other tissues and incubated at $4^{\circ} \mathrm{C}$ with gentle agitation in a modified Bouin's/glutaraldehyde fixative ( $2 \%$ glutaraldehyde, $25 \%$ saturated picric acid, and $1 \%$ glacial acetic acid) for $1-4 \mathrm{hr}$, washed 3 times in $0.4 \%$ saponin-PBS for $30 \mathrm{~min}$ each, and taken through an ethanol dehydration series at $4^{\circ} \mathrm{C}$. Fixed specimens were incubated in collagenase $(1 \mathrm{mg} / \mathrm{ml}$; Sigma type XI) for $24 \mathrm{hr}$ and then blocked overnight with goat serum ( $5 \mathrm{mg} / \mathrm{ml}$; Sigma lot\# 28F-9401) in $0.4 \%$ saponin-PBS (+1.0\% BSA).

A 3-tier antibody system using the PAP method (Vandesande, 1979) was employed to identify cells with CAP-like immunoreactivity. Primary antibody (6C5; dilution 1:1000), secondary antibody (whole molecule, goat anti-mouse IgG; dilution 1:1000), and tertiary antibody (mouse peroxidase antiperoxidase (PAP; dilution 1:1000) were suspended in $0.4 \%$ saponin-PBS (with $1 \% \mathrm{BSA}$ ). Each antibody suspension was incubated for $24 \mathrm{hr}$ at $4^{\circ} \mathrm{C}$ with constant gentle agitation. Specimens were washed 5 times in $5 \mathrm{hr}$ with $0.4 \%$ saponin-PBS (with $1 \%$ BSA) between successive incubations. Following equilibration in 3,3'-diaminobenzidine (DAB), immunoreactivity was visualized by incubation in a solution of $0.8 \%$ saponin-PBS containing $\mathrm{DAB}(0.5 \mathrm{mg} / \mathrm{ml})$ and hydrogen peroxide $(0.003 \%)$ until complete, usually $10-15 \mathrm{~min}$. Visualized preparations were taken through an ethanol dehydration series, equilibrated in xylene, and mounted in Permount for observation with Nomarsk optics.

CAP extraction. The abdominal portions of 25 VNCs (ANCs), including the fused terminal ganglion, were removed from day 3 fifthinstar caterpillars, blotted dry, and frozen in liquid nitrogen. Each ganglion was microdissected into medial and lateral strips as described below and stored separately at $-20^{\circ} \mathrm{C}$ for no more than several weeks. A few phenylthiourea crystals were added to the frozen tissue to inhibit tyrosinase activity (Williams, 1959). After thawing, each sample was heat-treated in a small volume of acidified methanol $(20 \mu \mathrm{l} / \mathrm{ANC})$ for $5 \mathrm{~min}$ at $80^{\circ} \mathrm{C}$, placed on ice, and homogenized in a ground-glass homogenizer. The homogenate was centrifuged for $15 \mathrm{~min}$ at $4^{\circ} \mathrm{C}(12,000$ $\times g$ ) and the supernatant collected. The pellet was resuspended in double-distilled water $\left(\mathrm{ddH}_{2} \mathrm{O} ; 10 \mu \mathrm{l} / \mathrm{ANC}\right)$, rehomogenized, centrifuged, and the resultant supernatant pooled together with that from the original extraction.

The combined supernatant fraction was loaded onto an $\mathrm{MeOH}-\mathrm{ac}-$ tivated, water-rinsed Waters C-18 Sep-pak cartridge and washed in 5 times its volume with $\mathrm{ddH}_{2} \mathrm{O}$. This was followed by stepwise applications of $20 \%$ and $80 \%$ acetonitrile (Baker; $\mathrm{HPLC}$ grade) in dd $\mathrm{H}_{2} \mathrm{O}$. From previous studies, it was demonstrated that both CAPs elute in the $80 \%$ acetonitrile fraction (Tublitz and Truman, 1985c, d). Accordingly, this fraction was collected, frozen in dry ice, and lyophilized to powder. Lyophilized samples were stored at $-20^{\circ} \mathrm{C}$ for up to a week before use.

High-pressure liquid chromatography (HPLC). After Sep-pak treatment and lyophilization, extracts of lateral and medial portions of larval nerve cords were hydrated in $500 \mu 1$ of $20 \%$ acetonitrile in $\mathrm{ddH}_{2} \mathrm{O}+$ $0.1 \%$ trifluoroacetic acid and chromatographed through a $\mathrm{C}-18$ reversephase HPLC column (Brownlee Aquapore $300-\mu \mathrm{m}$ column, $4.6 \times 220$ $\mathrm{mm}$ ). Once the sample was loaded, a 2 -stage, linear acetonitrile-water gradient was applied with $0.1 \%$ trifluoroacetic acid as the counter ion. The 50 -min gradient began at a concentration of $20 \%$ acetonitrile $/ 80 \%$ water with the acetonitrile concentration increasing at a rate of $1 \% \mathrm{~min}^{-1}$ for the first $30 \mathrm{~min}$, and changing to $2 \% \mathrm{~min}^{-1}$ for the following $20 \mathrm{~min}$. For each chromatography run, $501-\mathrm{ml}$ fractions were collected at $1-\mathrm{min}$ intervals. Each fraction was then lyophilized, stored at $-20^{\circ} \mathrm{C}$, and later resuspended in Manduca saline for bioassay on the pharate adult heart.

Ganglion microdissection. Individual unfused, abdominal ganglia from either day $3 \mathrm{ffth}$-instar larvae or day 8 developing adults were frozen in liquid nitrogen and longitudinally sectioned with a razor blade chip into 3 equivalent strips. Each strip was individually sonicated, heattreated at $80^{\circ} \mathrm{C}$ for $5 \mathrm{~min}$, and centrifuged at $12,000 \times \mathrm{g}$ for $3 \mathrm{~min}$. The supernatant was then removed and bioassayed for CAP bioactivity on the isolated Manduca heart.

Cell cluster/cell body bioassays. Feeding larvae (day 3, fifth instar) or developing male adults (day 8 ) were anesthetized by immersion in cold water or chilling on ice, respectively, prior to dissection. Animals were opened ventrally and the posterior 3 unfused abdominal ganglia (A3A5) removed. Each ganglion was then transferred to a small Sylgardcontaining, plastic Petri dish and pinned using minute pins and individual glass fibers while immersed in paraffin oil. A drop of Manduca saline containing 3\% collagenase/dispase (Boehringer-Mannheim) was then placed on the ganglion for $5 \mathrm{~min}$ and subsequently removed by several rinses in normal saline. The ganglion was then manually desheathed using fine forceps. Following desheathing, individual lateral and midline cells could be easily visualized using dark-field optics. The lateral and posterior medial neurosecretory neurons were especially prominent because of the opalescent nature of their somata, a property characteristic of many invertebrate neurosecretory cells (Rowell, 1976). Earlier work demonstrated that both the lateral "bursicon" and posterior medial cells persist throughout adult development (Taylor and Truman, 1974; Taghert and Truman, 1982b). This result was confirmed by following lateral cells in abdominal ganglia throughout adult development using standard histological procedures. We found that the number and the position of the lateral neurosecretory cells remained unaltered during adult development and that no necrotic profiles, characteristic of dying cells, were seen in the region of the lateral cells at any postmetamorphic stage (N. J. Tublitz, unpublished observations). Taghert and Truman (1982b) documented that the lateral cells were individually identifiable on the basis of soma size and relative cell body position within the ganglion. For all experiments involving single lateral cells, we used the anteriormost lateral cell, cell \#26 (from the nomenclature of Taylor and Truman, 1974). Cell \#26 can always be distinguished from cell \#27 (Taghert and Truman, 1982b) in that cell \#26 is always located within the lateral cell group whereas cell \#27 is usually found by itself, with a more anteriorly and centrally placed cell body.

After enzymatic treatment and desheathing, cell clusters or individual cell bodies were isolated from the ganglion using fine glass probes and transferred through the oil into small volumes of distilled water (2-5 $\mu 1)$ to promote cell lysis (Berlind and Maddrell, 1979; Taghert and Truman, 1982b). An equivalent amount of twice-concentrated Manduca saline was added to each sample prior to freezing at $-20^{\circ} \mathrm{C}$. Immediately prior to bioassaying for either bursicon or CAP activity, samples were thawed and vortexed, and in the case of the heart bioassay, sample volume was increased to $50 \mu \mathrm{l}$ with Manduca saline.

Bursicon bioassay. The bioassay for bursicon activity was modified only slightly from that used in previous studies (Truman, 1973; Reynolds, 1977, 1983; Taghert and Truman, 1982a). The mesothoracic wings were removed from pharate adult animals $1-2 \mathrm{hr}$ prior to adult eclosion, the time when the wings were extremely responsive to bursicon (Reynolds et al., 1979). Each wing received a 10- $\mu$ l injection of either saline or the test material into the lumen of the costal vein followed by incubation in a moist chamber for $3 \mathrm{hr}$. After the incubation period, wing scales were removed with melted paraffin under $70 \%$ ethanol to allow visualization of the wing veins. Bursicon activity of test and control samples was scored on an arbitrary scale of $1-5$ based on the yellow coloration of the cuticle of the wing veins. Quantification was determined by comparing activity in control and test injected wings and by serial dilution of samples.

\section{Results}

Immunocytochemical identification of CAP-containing cells

As a first step toward the identification of cells in abdominal ganglia that synthesize and secrete the CAP(s), we stained both larval and pharate adult unfused abdominal ganglia with a monoclonal antibody specifically directed against the CAPs (Taghert et al., 1983, 1984), using a standard 3-tiered antibody staining procedure described in Materials and Methods. In day 1 fifth-instar larvae, the first full day after molting from the penultimate 4 th instar, we found 5 pairs of CAP-immunoreactive cell bodies in each unfused abdominal ganglion, consisting of 4 pairs along the ganglionic lateral margin and 1 bilateral pair on the midline (Fig. 1, C, D). In trials with very low background, we observed that each immunoreactive midline neuron had a bifurcating axon that exited the ganglion into both ipsi- and contralateral ventral nerves (VNs), whereas the lateral cells appeared to send a single unbranched process out the ipsilateral VN only (data not shown). CAP-like immunoreactivity was also occasionally found in the proximal portion of the $\mathrm{VN}$, in the VN branch leading to the TN, and in the TN itself.

Based on their morphologies it was possible to unequivocally 


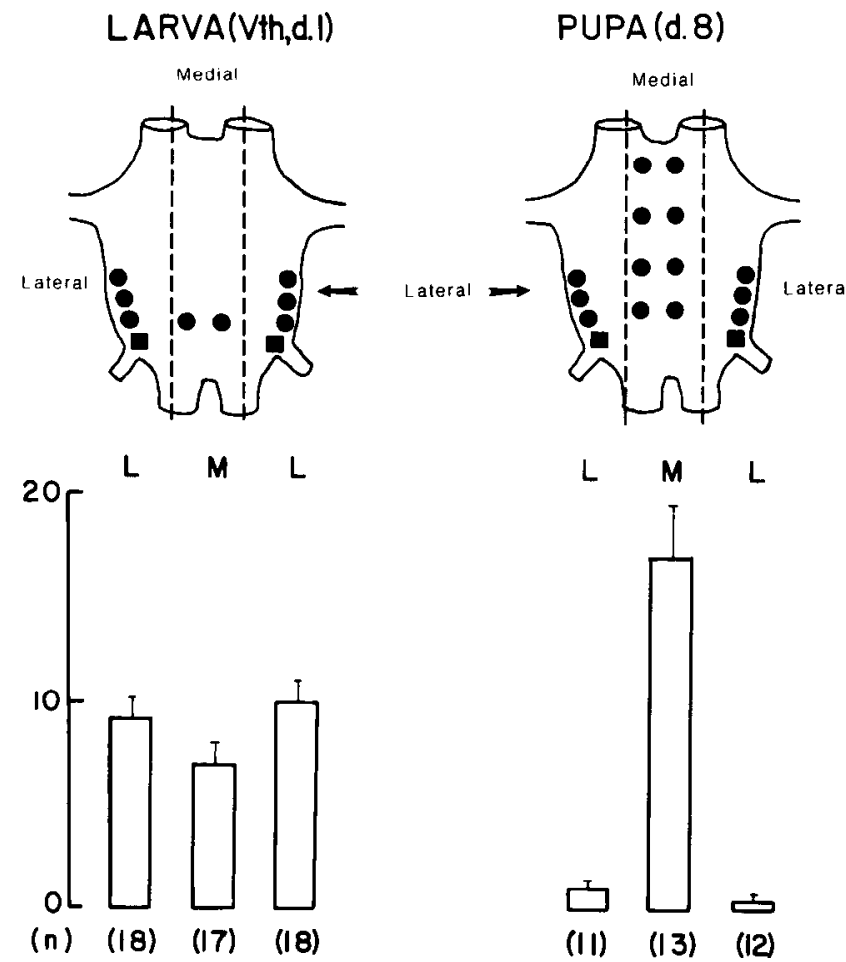

Figure 2. CAP-like bioactivity in lateral and medial regions of abdominal ganglia in larvae and pupae. Upper panel, Diagrammatic representation of a larval (day 1 fifth instar) and pupal (day 8) unfused abdominal ganglion showing cell body locations of transverse nerve projecting neurons. $L$, Lateral; $M$, medial; $V t h d . l$, day 1 fifth instar; d.8, pupal day 8 . Ganglia were microdissected as described in Materials and Methods and bioactivity determined on the isolated heart bioassay (Tublitz and Truman, 1985a). Each histogram represents CAP activity (mean + SEM) from a single region of the ganglion.

identify the medial and lateral immunoreactive cells found in larvae. The pair of immunoreactive posteriomedial somata with bilateral axons exiting the ganglion via the $\mathrm{VN}$ and projecting to the TN was unmistakably recognized as the lone pair of medial adult CAP cells that arise and mature during embryogenesis (Taghert and Truman, 1982b; Tublitz and Truman, 1985c, d), since there are no other cells in the ganglion with those characteristics (Fig. 1A; Taylor and Truman, 1974; Taghert and Truman, 1982b). What was surprising was that the 4 pairs of lateral, CAP-immunoreactive cells in caterpillars were clearly the bursicon-containing neurons, neurosecretory cells described by Taghert and Truman (1982a) with ipsilateral axons that terminate in the TN and which persist without major morphological changes throughout adult development (Fig. 1, $A, B$; Taghert and Truman, 1982b). That these larval CAP-immunoreactive cells were the bursicon-containing cells of Taghert and Truman (1982a, b) was based on several criteria, including cell body size and position along the lateral margin of the ganglion at the point where the VN exits, axonal projections to the TN, and the unique shape of their dendritic arborizations, visible in a few of our immunocytochemical preparations.

In contrast to our results in larvae, a markedly different pattern was revealed (Fig. $1 E$ ) when the identical immunochemical protocol was used on day 8 pupae, the stage during metamorphosis when the full complement of adult cells is already present and mature (Taylor and Truman, 1974): four pairs of midline cells, known from other studies to be CAP-containing neurons
(Tublitz and Truman, $1985 \mathrm{c}$, d), were strongly CAP-immunoreactive while the lateral neurosecretory cells no longer exhibited any demonstrable immunostaining despite their persistence into the adult stage (Taylor and Truman, 1974; Taghert and Truman, $1982 a, b)$. These data imply that the lateral cells might be expressing a CAP-like antigen in a stage-specific manner.

\section{CAP-like bioactivity in lateral and medial regions of abdominal ganglia}

To test the hypothesis that the lateral cells in 5th-instar larvae might be synthesizing a CAP-like factor, we microdissected larval (day 1, fifth instar) and pupal (day 8) abdominal ganglia into medial and lateral strips which were pooled and processed for CAP bioactivity according to the procedure described in Materials and Methods. Day 8 pupae were chosen because it is the first stage during metamorphosis when the full complement of adult cells is present (Taylor and Truman, 1974), including the 3 pairs of midline CAP neurons that arise postembryonically (Taghert and Truman, 1982a; Tublitz and Truman, 1985b-d). All samples were tested for cardioacceleratory activity on the isolated pharate adult Manduca heart, previously demonstrated to be a highly sensitive and specific bioassay for CAP activity (Tublitz and Truman, 1984, 1985a-d; Tublitz and Evans, 1986; Tublitz, 1989). Our results, depicted in Figure 2, indicate that CAP-like activity was evenly distributed across larval ganglia, with virtually equivalent amounts of cardioexcitatory activity in lateral and medial regions. In pupal day 8 animals, however, over $90 \%$ of CAP-like bioactivity was localized to the medial region of the ganglion, the location of the 4 pairs of adult CAPcontaining neurons (Tublitz and Truman, 1985c) including the 6 cells that mature postembryonically during adult development (Taylor and Truman, 1974; Taghert and Truman, 1982b). Lateral regions from pupal ganglia were almost completely lacking in CAP-like bioactivity (Fig. 2).

\section{Biochemistry of CAP bioactivity in 5th-instar larvae}

To determine whether the cardioacceleratory activity in lateral and posterior midline cells in larvae was due to the same molecular species of CAP, larval ganglia were microdissected into medial and lateral strips, homogenized, and chromatographed on an HPLC C-18 reverse-phase column (Aquapore RP-300, Brownlee). A linear gradient of water/acetonitrile and $0.1 \%$ trifluoroacetic acid as the counter ion, a procedure previously shown to separate the 2 known CAPs from each other (Tublitz and Evans, 1986), was used. HPLC fractions were then bioassayed on an isolated Manduca heart for CAP activity. Figure 3 shows that lateral and medial portions of larval (day 3 , fifth instar) ganglia cach containcd only a single pcak of cardioacceleratory activity, both of which coeluted with that of $\mathrm{CAP}_{2}$ isolated from either whole larval or pharate adult ganglia (Fig. 3). Cardioexcitatory bioactivity associated with $\mathrm{CAP}_{1}$ elution times was not detected in either partial or intact larval ganglia and no other cardioacceleratory peaks were found. The results from the HPLC experiments indicate that only a single species of CAP is present in premetamorphic 5th-instar larvae.

\section{$C A P_{2}$ bioactivity in lateral and medial cell clusters and in individually isolated cell bodies}

Having demonstrated that a CAP-like antigen was expressed in lateral cells only in larvae and that this antigen was likely to be $\mathrm{CAP}_{2}$, we were interested in determining whether the lateral neurosecretory cells exhibited any $\mathrm{CAP}_{2}$-like bioactivity. To test 


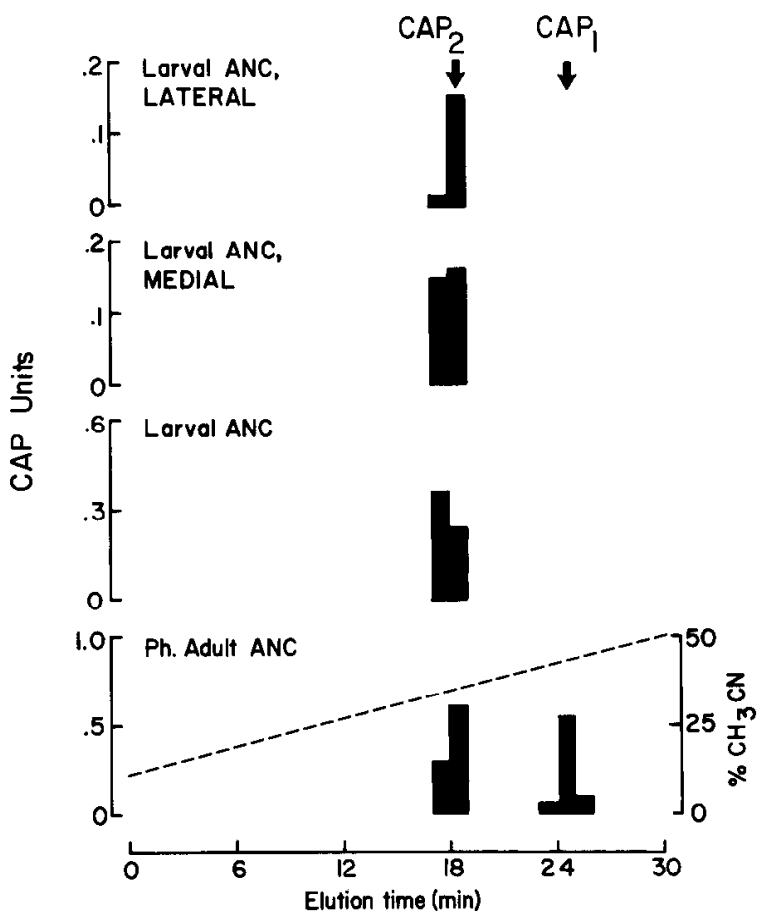

Figure 3. Isolation and identification of CAP bioactivity from portions of larval ganglion using HPLC. Abdominal portions of the ventral nerve cord $(A N C)$ in day 3 fifth-instar larvae were surgically microdissected into medial and lateral strips and purified for CAP bioactivity as dcscribed in Materials and Methods. Lateral, lateral portion of larval ganglia (day 3 fifth instar); medial, medial section of larval ganglia (day 3 fifth instar); larval $A N C$, intact larval (day 3 fifth instar) ganglia; $P h$. adult $A N C$, intact pharate adult ANC. Note that lateral and medial regions of larval ganglia each contain only 1 peak of cardioexcitatory activity and that both coelute with $\mathrm{CAP}_{2}$ isolated from adults.

this hypothesis, we initially measured CAP levels from small clusters of cell bodies isolated from larval or pupal abdominal ganglia. Three groups of neurons, each of which was visualizable under a dissecting microscope, were used in these experiments: the lateral bursicon-containing cells; the embryonically derived, midline CAP-containing neurons that lay at the posterior end of the ganglion (Taylor and Truman, 1974; Tublitz and Truman, $1985 \mathrm{c}, \mathrm{d}$ ); and a set of 5 anteriomedial cell bodies previously shown to be motoneurons innervating intersegmental muscles (Levine, 1987). Each group of cells in larvae was easily identifiable in situ with dark-field illumination using cell body position and soma size as criteria (refer to Materials and Methods for details); however, owing to the massive ganglionic reorganization associated with metamorphosis (Taylor and Truman, 1974; Levine, 1987), only the lateral cells were still visible by pupal day 8 and, hence, were the only group of cells we assayed in pupae. After isolation, each cell cluster was assayed for CAP bioactivity on the in vitro Manduca heart.

Our results showed that measurable levels of CAP bioactivity were present in lateral and posterior medial cell clusters taken from larval ganglia (Fig. 4). Each lateral cluster in larvae contained about twice as much CAP-like bioactivity as that found in the midline cells (Fig. 4). In contrast, virtually no CAP-like bioactivity was found in lateral cell clusters removed from pupal day 8 animals. The control cells, the cluster of larval anteriomedial neurons, produced no change in heart rate when assayed on the isolated pharate adult heart and, therefore, were considered to be devoid of CAP activity (Fig. 4).
LARVA(Vth,d.I)

PUPA (d. 8)
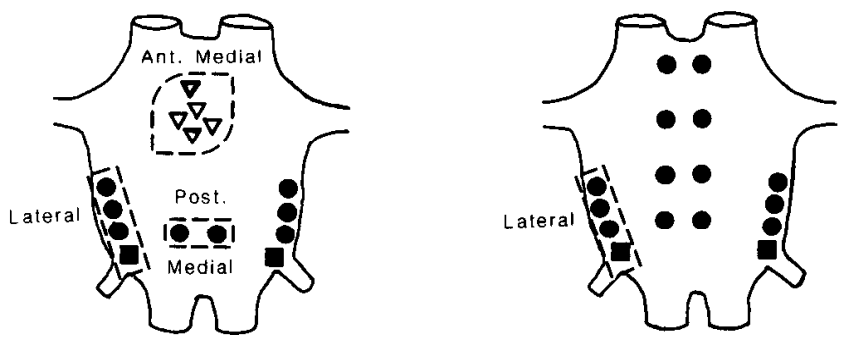

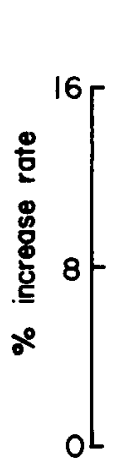

(n)
Lat

Post. Ant

Med. Med

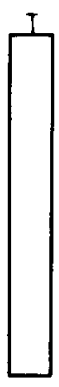

(6)

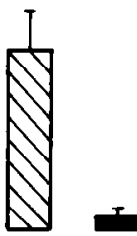

(8)
(6)
Lot.

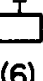

(6)
Figure 4. CAP levels of cell clusters removed from larval and pupal animals. Lat., The 4 pairs of opalescent neurosecretory cells previously identified unambiguously as synthesizing and secreting bursicon (Taghert and Truman, 1982a, b); Post. Med., the 2, bilaterally symmetrical, posterior midline somata that arise during embryonic neurogenesis and persist throughout all postembryonic stages, and shown earlier to contain CAP bioactivity (Tublitz and Truman, 1985c, d; Tublitz and Sylwester, 1988); Ant. Med., a set of 5-6 large motoneuron somata lying along the anterior midline. Each cluster is easily isolated in larval ganglia, but owing to the massive ganglionic reorganization associated with metamorphosis (Levine, 1987), only the lateral clusters remain visible by pupal day 8 . Abbreviations as described in Figure 2. Each histogram represents CAP activity (mean + SEM) in a single cluster

Similar results were found when individual lateral or medial cells were dissected and their contents assayed for CAP activity using procedures previously described (Berlind and Maddrell, 1979; Taghert and Truman, 1982b). Measurable quantities of CAP-like bioactivity were detected in single lateral and posterior midline cells removed from larvae (Fig. 5), with equivalent amounts of activity present in each cell type. By contrast, individual lateral cells from pupal day 8 ganglia exhibited little detectable CAP-like bioactivity (Fig. 5). The cell cluster and single-cell bioassays unequivocally demonstrate that the lateral cells in caterpillars contain significant levels of CAP-like bioactivity, which disappear by pupal day 8 , midway through adult development.

\section{Bursicon and CAP levels in single lateral cells from larvae and developing adults}

Having shown that the level of CAP activity in the lateral cells was stage-specific, we were also interested in determining whether these neurosecretory cells were capable of modulating their levels of bursicon. For these experiments individual lateral cells were again dissected free of surrounding tissues using the protocol described in Materials and Methods. Following dissection and cell lysis, the contents of each cell were divided into 2 equal 

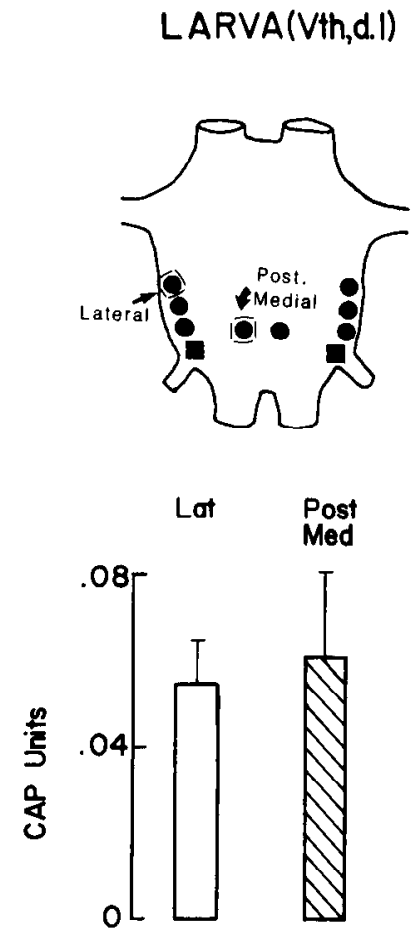

(n) (7)

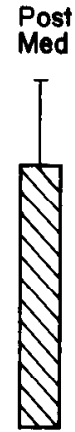

(6)

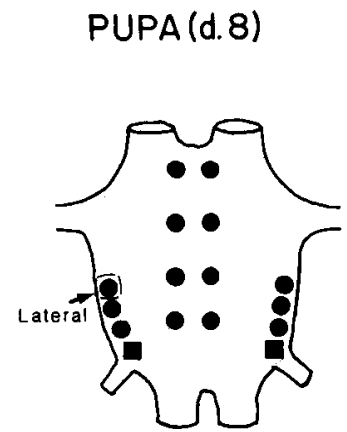

Lat

Figure 5. CAP levels in single, identifiable neurons isolated from larval and pupal ganglia of the tobacco hornworm, Manduca sexta. Experimental details and explanations of the abbreviations are found in $\mathrm{Ma}$ terials and Methods and in the captions to Figures 2 and 4. Each histogram represents the mean + SEM of CAP activity in a single cell. The number of replicates is listed below each histogram in parentheses. Although both lateral and posterior midline neurons are readily visible in larvae under a dissecting microscope, it proved impossible to unequivocally identify the posterior medial cells at pupal day 8 because of the major anatomical and physiological reorganization of ventral ganglia during metamorphosis (Levine, 1987).

aliquots, 1 of which was analyzed for CAP content on the in vitro heart bioassay while the second aliquot was assayed for bursicon activity on the isolated pharate adult wing. Our results, depicted in Figure 6, indicate that individual lateral cells in 5thinstar larvae contained fairly low levels of bursicon $(<0.007$ bursicon unit where 1 unit equals the amount of bursicon in the abdominal portion of a pharate adult nerve cord) and a relatively high amount of CAP. However, when the same cell was removed from animals midway through adult development (pupal day 8) and assayed for bursicon and CAP, the reverse was seen: lateral cells in pupae exhibited high levels of bursicon (ca. 0.1 bursicon unit) while containing virtually no detectable CAP activity (Fig. 6).

\section{Discussion}

The temporal expression of $\mathrm{CAP}_{2}$ and bursicon in lateral neurosecretory cells in the Manduca VNC during adult development

Using microdissection techniques, individual cell body assays, and biochemical procedures, Taghert and Truman (1982a, b) established that there are 4 pairs of lateral neurosecretory cells in each Manduca ventral ganglion that synthesize and secrete the insect tanning hormone, bursicon (Truman, 1973; Reynolds, 1977, 1983; Reynolds et al., 1979). Their data indicated that

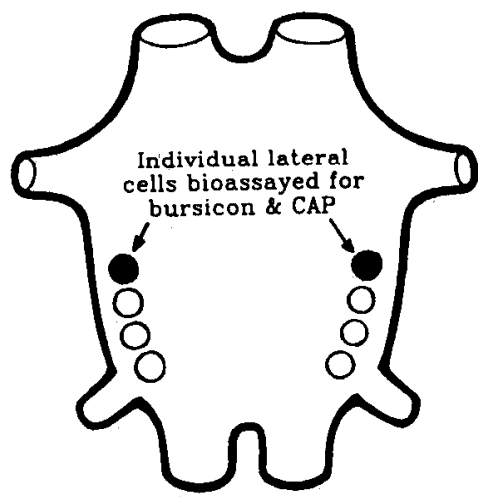

BURSICON LEVELS

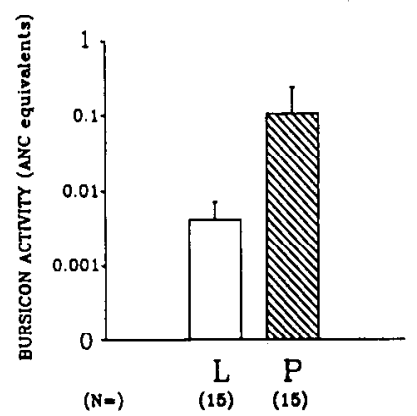

Figure 6. CAP and bursicon levels in single, lateral neurosecretory neurons isolated from larval and pupal ganglion in Manduca. After isolation, the cell contents of each neuron were assayed for bursicon and CAP activities using the procedures described in Materials and Methods. Refer to the captions of Figures 2, 4, and 5 for additional details. $L$, Larval day $3 ; P$, pupal day 8 . Each histogram represents the mean + SEM of biological activity.

these peptidergic cells, which persist throughout metamorphosis (Taylor and Truman, 1974; Taghert and Truman, 1982b), apparently expressed bursicon bioactivity during all postembryonic stages.

Three independent lines of evidence presented here suggest that bursicon is not the only neuropeptide produced in these cells. First, immunocytochemical results showed that the lateral cells are strongly CAP immunoreactive in larvae (Fig. 1, C, D). Second, biochemical analyses using HPLC of a small cluster of cells, including the lateral neurons, from larval ganglia revealed a single cardioactive peak that coelutes with $\mathrm{CAP}_{2}$ (Fig. 3). Third, bioassay of whole or partial ganglia (Fig. 2), lateral cell clusters (Fig. 4), or individual lateral neurons (Fig. 5) indicated the presence of a $\mathrm{CAP}_{2}$-like cardioacceleratory factor.

Results from other studies also lend credence to the idea that the lateral cells in larvae synthesize $\mathrm{CAP}_{2}$. The same anti-CAP immunocytochemical staining pattern described here, including intensely staining lateral cells, was also seen in other larval stages (Edwards et al., unpublished observations) and in embryos (Broadie et al., 1989). These reports also showed that the antiCAP immunostaining pattern in the embryonic and larval CNS could be blocked only by preincubation with $\mathrm{CAP}_{2}$ and that CAP-like bioactivity could be immunoprecipitated by the antiCAP antibody (Broadie et al., 1989; Edwards et al., unpublished observations). Taken together, these data provide strong evi- 
dence that the lateral neurosecretory neurons in the ANC of 5th-instar Manduca caterpillars express CAP $_{2}$

Our results also support the notion that the lateral cells express $\mathrm{CAP}_{2}$ in a stage-specific manner. Although the lateral cells were strongly CAP immunopositive in feeding 5 th-instar caterpillars (Fig. 1, $C, D$ ), a marked decrease in CAP immunoreactivity of the lateral cells was seen following pupation, and by the end of adult development these cells no longer stained with the antiCAP antibody (Fig. 1E). CAP measurements of lateral cell clusters (Fig. 4) or of individual lateral neurons (Fig. 5) showed that these cells contained high levels of CAP in larvae, but were essentially devoid of CAP bioactivity by pupal day 8 . Hence, our immunocytochemical and physiological results demonstrate that $\mathrm{CAP}_{2}$ is expressed in the lateral neurosecretory neurons of Manduca in a stage-specific manner.

Finally, bioassay of single larval or pupal lateral cells for bursicon and CAP activities showed that these neurosecretory cells synthesized primarily $\mathrm{CAP}_{2}$ in larvae (Figs. 5 and 6). However, these same neurons, when assayed midway through adult development, expressed high levels of bursicon and exhibited no detectable $\mathrm{CAP}_{2}$ activity (Fig. 6). These results demonstrate that the lateral cells undergo a qualitative change in transmitter expression associated with metamorphosis.

\section{Identification of individual lateral cells}

The major conclusion of this paper, that the lateral cells alter their transmitter phenotype during adult development in Man$d u c a$, rests on the assumption that the same neuron can be repeatedly identified in larvae and pupae. Based on earlier histochemical (Taylor and Truman, 1974) and extracellular backfilling data (Taghert and Truman, 1982b), there is no evidence that metamorphosis either induces the death of lateral neurosecretory cells in larvae or initiates the appearance of new, postembryonically derived lateral neurosecretory cells in pupae. Histological sectioning of ganglia taken at various times throughout adult development confirms the results of these earlier studies (Tublitz, unpublished observations). Moreover, Taghert and Truman (1982a, b) showed that the 4 lateral cells, which in situ are highly opalescent, could be individually distinguished based on soma size and relative position in the ganglion. Thus, the single-cell experiments described here, which focused on the anteriormost opalescent cell in the lateral neurosecretory cluster, cell \#26, were performed with a high degree of assurance that the same cell could be routinely identified in different animals.

\section{Are the lateral cells terminally differentiated in larvae?}

One important issue raised by this work concerns the state of differentiation of these lateral cells in larvae, and the evidence suggests that these cells are probably fully differentiated prior to metamorphosis. The CNS of a holometabolous insect such as Manduca undergoes a major transformation during metamorphosis, including de novo neurogenesis, programmed death of neurons, the growth or regression of neuronal arbors, and the reorganization of synaptic connections (e.g., Truman, 1983; Levine and Truman, 1985; Booker and Truman, 1987; Levine, 1987; Weeks, 1987). Some fully mature, i.e., functional, larval neurons die (Weeks and Truman, 1985), others are functionally respecified (Levine, 1987), and still others remain relatively unaltered throughout adult development (Levine and Truman, 1985). Neurons that are physiologically active in the larva are, therefore, subject to a variety of fates during adult development, including dedifferentiation and redifferentiation, and the lateral cells appear to fall into this latter category. Broadie et al. (1989) demonstrated that the lateral cells have already reached their peripheral target, the TN, by the latter part of embryogenesis, and other studies have shown that this remains the only target of these cells throughout postembryonic life (Taylor and Truman, 1974; Taghert and Truman, 1982a; N. J. Tublitz and P. $\mathrm{K}$. Loi, unpublished observations). Their central arbors are also complete by the end of embryogenesis and are not drastically altered postembryonically (Taghert and Truman, 1982a; Tublitz and Loi, unpublished observations). Most important, these cells are functionally active both in the embryo (Broadie et al., 1989) and in 5th-instar larvae (N. J. Tublitz, K. K. Edwards, D. P. Kimble, and A. W. Sylwester, unpublished observations), releasing $\mathrm{CAP}_{2}$ to regulate hindgut motility. Thus, from a morphological and physiological standpoint these cells appear to be mature and fully differentiated prior to changing their transmitter profile. Taken together, the results presented here coupled with those from other investigators (Taghert and Truman, 1982a, b) strongly support the notion that these particular neurosecretory cells modify their transmitter phenotype postembryonically, producing high amounts of $\mathrm{CAP}_{2}$ and low levels of bursicon in larvae and only the latter in pupae. These data directly confirm the long-standing belief that an individual neuron not only has the capacity to, but actually does, undergo a major alteration of its secretory profile in vivo after the completion of embryogenesis. Recent preliminary data (Tublitz and Sylwester, 1988 ) indicate that the drop of CAP bioactivity and the rise in bursicon levels follow different time courses during the first half of adult development. This result suggests that regulation of the synthesis and release of the 2 neuropeptides may be independently controlled, and not a simple negative feedback loop where the appearance of 1 causes the decline of the other (Tublitz and Sylwester, 1988). Given that the switch in transmitter phenotype occurs at metamorphosis, it is likely that the changes in the hormonal milieu at this time might be responsible for triggering this biochemical transformation; experiments are currently underway to test this hypothesis.

\section{References}

Bell, R. A., and F. A. Joachim (1976) Techniques for rearing laboratory colonies of tobacco hornworms and pink bollworms. Ann. Ent. Soc. America 69: 365-373.

Berlind, A., and S. H. P. Maddrell (1979) Changes in hormonal activity of single neurosecretory cell bodies during physiological secretion. Brain Res. 161: 459-467.

Broadie, K. S., A. W. Sylwester, M. Bate, and N. J. Tublitz (1989) Immunological, biochemical, and physiological analyses of cardioacceleratory peptide $2\left(\mathrm{CAP}_{2}\right)$ activity in the embryo of the tobacco hawkmoth, Manduca sexta. Development (in press).

Coulombe, J. N., and M. Bronner-Fraser (1986) Cholinergic neurones acquire adrenergic neurotransmitters when transplanted into an embryo. Nature 324: 569-572.

Gesser, B. P., and L.-I. Larsson (1985) Changes from enkephalin-like to gastrin/cholecystokinin-like immunoreactivity in snail neurons. J. Neurosci. 5: 1412-1417.

Johnson, M., D. Ross, M. Meyers, R. Rees, R. Bunge, E. Wakshull, and H. Burton (1976) Synaptic vesicle cytochemistry changes when cultured sympathetic neurons develop cholinergic interactions. Nature 262: 308-310.

Koizumi, O., and H. Bode (1986) Plasticity in the nervous system of adult hydra. I. The position-dependent expression of FMRFamidelikc immunorcactivity. Dcv. Biol. 116: 407-421.

Landis, S., and D. Keefe (1983) Evidence for neurotransmitter plasticity in vivo: Developmental changes in properties of cholinergic sympathetic neurons. Dev. Biol. 98: 349-372. 
Leblanc, G., and S. Landis (1986) Development of choline acetyltransferase in the sympathetic innervation of rat sweat glands. J. Neurosci. 6: 260-265.

Levine, R. B. (1987) Neuronal reorganization and its endocrine control during insect metamorphosis. Curr. Topics Dev. Biol. 21: 341-365.

Levine, R. B., and J. W. Truman (1985) Dendritic reorganization of abdominal motoneurons during metamorphosis of the moth, Manduca sexta. J. Neurosci. 5: 2424-2431.

Lichtman, J. W., L. Magrassi, and D. Purves (1987) Visualization of neuromuscular junctions over periods of several months in living micc. J. Ncurosci. 7: 1215-1222.

Patterson, P. H. (1978) Environmental determination of autonomic neurotransmitter functions. Annu. Rev. Neurosci. 1: 1-17.

Patterson, P. H., and L. L. Y. Chun (1977) The induction of acetylcholine synthesis in primary cultures of dissociated sympathetic neurons. II. Developmental aspects. Dev. Biol. 60: 473-481.

Potter, D. D., S. C. Landis, and E. J. Furshpan (1980) Dual function during development of rat sympathetic neurons in culture. J. Exp. Biol. 89: 57-71.

Potter, D. D., S. Landis, S. G. Matsumoto, and E. J. Furshpan (1986) Synaptic functions in rat sympathetic neurons in microcultures. II. Adrenergic/cholinergic dual status and plasticity. J. Neurosci. 6: 10801098.

Raabe, M. (1982) Insect Neurohormones, Plenum, New York.

Raabe, M., M. Cazal, D. Chalaye, and N. de Besse (1966) Action cardioacceleratrice des organs neurohemaux perisympathetique ventraux des quelque insectes. C. R. Acad. Sci. Paris 263: 2002-2005.

Reynolds, S. E. (1977) Control of cuticle extensibility in the wings of adult Manduca at the time of eclosion: Effects of eclosion hormone and bursicon. J. Exp. Biol. 70: 27-39.

Reynolds, S. E. (1983) Bursicon. In Endocrinology of Insects, R. G. H. Downer and H. Laufer, eds., pp. 235-248, Liss, New York.

Reynolds, S. E., P. H. Taghert, and J. W. Truman (1979) Eclosion hormone and bursicon titres and the onset of hormonal responsiveness during the last day of adult development in Manduca sexta. J. Exp. Biol 78: 77-86.

Rowell, H. F. (1976) Insect neurosecretory cells: Form and function. Adv. Insect Physiol. 12: 63-124.

Schotzinger, R. J., and S. Landis (1988) Cholinergic phenotype developed by noradrenergic sympathetic neurons after innervation of a novel cholinergic target in vivo. Nature 335: 637-639.

Stevens, L., and S. Landis (1987) Development and properties of the secretory response in rat sweat glands: Relationship to the induction of cholinergic function in sweat gland innervation. Dev. Biol. 123: 179-190.

Taghert, P. H., and J. W. Truman (1982a) The distribution and molecular characteristics of the tanning hormone bursicon in the tobacco hornworm, Manduca sexta. J. Exp. Biol. 98: 373-383.

Taghert, P. H., and J. W. Truman (1982b) Identification of the bursicon-containing neurones in abdominal ganglia of the tobacco hornworm, Manduca sexta. J. Exp. Biol. 98: 385-401.

Taghert, P. H., N. J. Tublitz, J. W. Truman, and C. S. Goodman (1983) Monoclonal antibodics to insect peptidergic ncurons. Soc. Neurosci. Abstr. 9: 314
Taghert, P. H., N. J. Tublitz, C. S. Goodman, and J. W. Truman (1984) Monoclonal antibodies that recognize cardioactive peptides in the moth, Manduca sexta. Soc. Neurosci. Abstr. 10: 152.

Taylor, H. M., and J. W. Truman (1974) Metamorphosis of the abdominal ganglion of the tobacco hornworm, Manduca sexta. J. Comp. Physiol. 90: 367-388.

Truman, J. W. (1973) Physiology of insect ecdysis: III. Relationship between the hormonal control of eclosion and tanning in the tobacco hornworm, Manduca sexta. J. Exp. Biol. 57: 805-820.

Tublitz, N. J. (1989) Insect cardioactive peptides: Neurohormonal regulation of cardiac activity by two cardioacceleratory peptides (CAPs) during flight in the tobacco hawkmoth, Manduca sexta. J. Exp. Biol. 142: $31-48$.

Tublitz, N. J., and P. D. Evans (1986) Insect cardioactive peptides: Cardioacceleratory peptide (CAP) activity is blocked in vivo and in vitro with a monoclonal antibody. J. Neurosci. 6: 2451-2456.

Tublitz, N. J., and A. W. Sylwester (1988) Plasticity of transmitter expression: Individually identified peptidergic neurons alter their transmitter phenotype during post-embryonic development in the moth. Soc. Neurosci. Abstr. 14: 28

Tublitz, N. J., and J. W. Truman (1984) The physiology and biochemistry of two cardioacceleratory peptides from the CNS of the tobacco hawkmoth, Manduca sexta. In Insect Neurophysiology and Neurochemistry, A. B. Borkovic and S. Kelley, eds., pp. 491-493, Plenum, New York.

Tublitz, N. J., and J. W. Truman (1985a) Insect cardioactive peptides. I. Distribution and molecular characteristics of two cardioacceleratory peptides in the tobacco hawkmoth, Manduca sexta. J. Exp. Biol. 114. $365-379$.

Tublitz, N. J., and J. W. Truman (1985b) Insect cardioactive peptides. II. Neurohormonal control of heart activity by two cardioacceleratory peptides (CAPs) in the tobacco hawkmoth, Manduca sexta. J. Exp. Biol. 114: 381-395.

Tublitz, N. J., and J. W. Truman (1985c) Intracellular stimulation of an identified neuron evokes peptide release in an insect. Science 228: 1013-1015.

Tublitz, N. J., and J. W. Truman (1985d) Identification of neurones containing cardioacceleratory peptides (CAPs) in the ventral nerve cord of the tobacco hawkmoth, Manduca sexta. J. Exp. Biol. 116. $395-410$.

Tublitz, N. J., K. K. Edwards, A. W. Sylwester, and S. E. Reynolds (1989) Insect cardioactive peptides: I. A comparison of the biochemical and molecular properties of cardioactive peptides in $\mathrm{Man}$ duca sexta larvae and adults. J. Exp. Biol. (submitted).

Vandesande, F. (1979) A critical review of immunocytochemical methods for light microscopy. J. Neurosci. Meth. 1: 3-23.

Weeks, J. C., and J. W. Truman (1985) Independent steroid control of the fates of motoneurons and their muscles during insect metamorphosis. J. Neurosci. 5: 2290-2300.

Williams, C. M. (1959) The juvenile hormone: I. Endocrine activity of the corpora allata of the adult cecropia silkworm. Biol. Bull. Mar. Biol. Lab. Woods Hole 116: 323-328. 